\title{
Inequality in Access to Improved Water Source: A Regional Analysis by Theil Index
}

\author{
Avik Sinha, Siddhartha K. Rastogi \\ Department of Economics, Indian Institute of Management Indore, Indore, India \\ Email:f11aviks@iimidr.ac.in, srastogi@iimidr.ac.in
}

Received 15 October 2015; accepted 27 November 2015; published 30 November 2015

Copyright (C) 2015 by authors and Scientific Research Publishing Inc.

This work is licensed under the Creative Commons Attribution International License (CC BY). http://creativecommons.org/licenses/by/4.0/

c) (i) Open Access

\begin{abstract}
This study applies Theil's second measure for looking into inequality in access to improved water source. This index allows inequalities to be broken up within and between groups. An analysis of 188 countries for the period 1990-2012 demonstrates three observations: first, decline in inequality in access to improved water source is characterized by both within-group and between-group inequality elements; second, between-group inequalities are at present the key contributor of the entire inequality scenario; and lastly, an inclusive study on within-group inequalities divulges the significant role played by Central and South American and Middle East countries towards increase in inequalities and countries pertaining to North America, Asia and Oceania, Africa, and Europe towards decline in inequalities.
\end{abstract}

\section{Keywords}

Improved Water Source, Theil Index, Inequality, Decomposition Analysis

\section{Introduction}

In the year 2013, the West-Indian state of Maharashtra and parts of other states suffered from a severe water crisis. However, that is not an aberration for India, as already there have been four droughts in India since the dawn of the new millennia [1]. This is especially worrisome for the nation, where more than half of the population is employed in agricultural sector and more than an eighth of the Gross Domestic Product (GDP) originates from the same [2].

Average annual per capita availability of water in India has reduced at an alarming rate and decreased to 1545 cubic meters per capita as per the 2011 census, which was 1816 cubic meters as the time of the 2001 census. This implies an alarmingly high fall rate of about 15 per cent. Beyond the receding quantity, the water quality has shown unpalatable levels of organic pollution in different river stretches across India [3]. 
From a sustainability point of view, the crisis seems to be even more severe. As Figure 1 depicts, India's Annual freshwater withdrawals as a percentage of the total per cent of internal resources already exceeds 50 per cent. As India is hoping to maintain a high GDP growth rate, pressure would further increase on water resources due to increasing population, urbanization and industrialization. In essence, India can be said to be undergoing a water-stress with a rush towards water-disaster.

This rate of freshwater withdrawal, along with possibly slower replenishment, is very high as compared to most other nations, including highly populated China and water-poor South Africa, as depicted in Figure 1. However, despite apparent better performance, countries world over are not necessarily doing great vis-à-vis protection, augmentation, and propagation of water resources. For example, despite more freshwater availability and lesser exploitation than India, China is far more vulnerable to water stress than India. The reason lies in the fact that it is home to $21 \%$ of the world's population but it contains only $7 \%$ of the world's freshwater supplies [5].

Water is not distributed evenly across the world and the water flow is often contrary to the population distribution. As depicted by Table 1 below, it is clear that despite a far lower population share, the average river runoff is much higher in some parts of the world. At the same time, it must be noted that a lot of this water is inaccessible, further increasing the water stress [6].

Water distribution and scarcity have been getting belated attention in the past sometime primarily due to climate change becoming a reality faster than expected. The Water Foot Print (WFP), a water intensity measure created by the WFP Network, depicts the volume of water needed for the production of goods and services consumed by the inhabitants of the country [7]. The WFP per capita map, as shown in Figure 2, shows that developed countries are the most water intensive. This figure shows green areas as less water intensive on per capita basis, whereas the movement towards red color depicts increase in water intensity. Since it is per capita basis, it must be seen in conjunction with Table 1 below, showing absolute availability of water. It is clear that on one hand the developing world is endowed with less water; the per capita availability is further lowered due to high

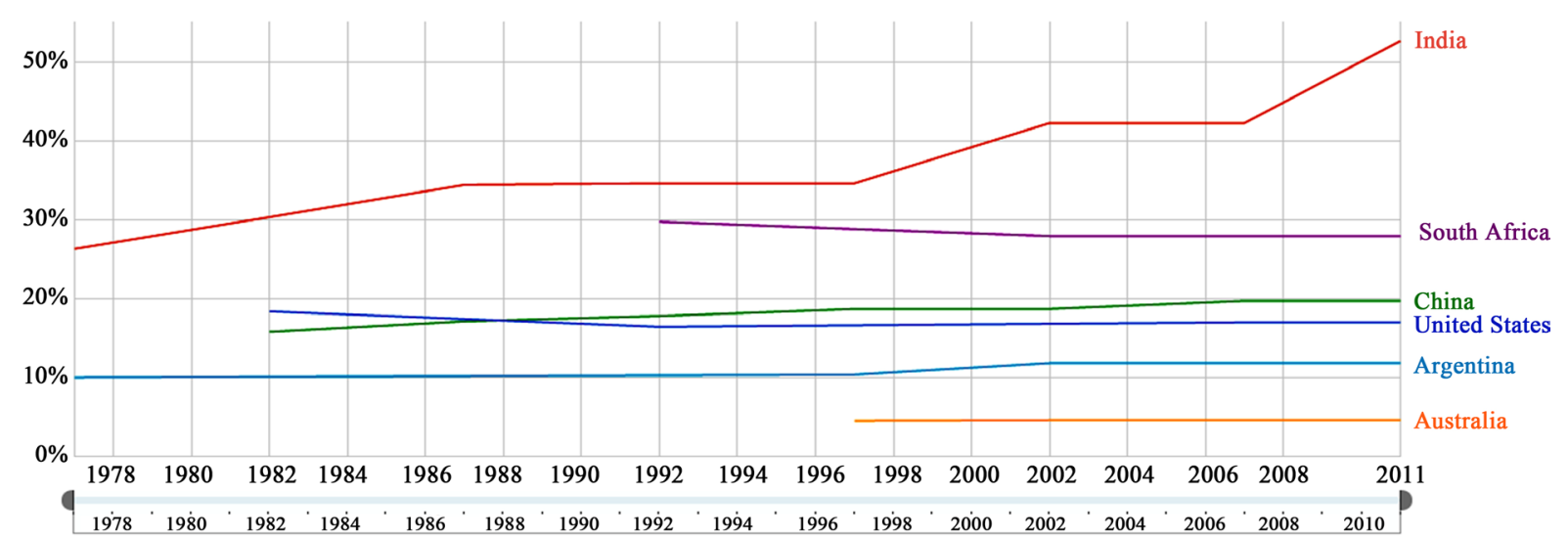

Source: Google Public Data [4], as per World Bank, 2015

Figure 1. Annual freshwater withdrawals, total (\% of internal resources).

Table 1. Continental breakdown of share of global runoff and population.

\begin{tabular}{cccc}
\hline Region & Total river runoff (\%) & Share of global river runoff (\%) & Share of global population (\%) \\
\hline Europe & 3240 & 8.0 & 13.0 \\
Asia & 14,550 & 35.8 & 60.5 \\
Africa & 4320 & 10.6 & 12.5 \\
North and Central America & 6200 & 15.2 & 8.0 \\
South America & 10,420 & 25.6 & 5.5 \\
Australia and Oceania & 1970 & 4.8 & 0.5 \\
Total & $\mathbf{4 0 , 7 0 0}$ & $\mathbf{1 0 0 . 0}$ & $\mathbf{1 0 0 . 0}$ \\
\hline
\end{tabular}

Source: Global Change [6]. 


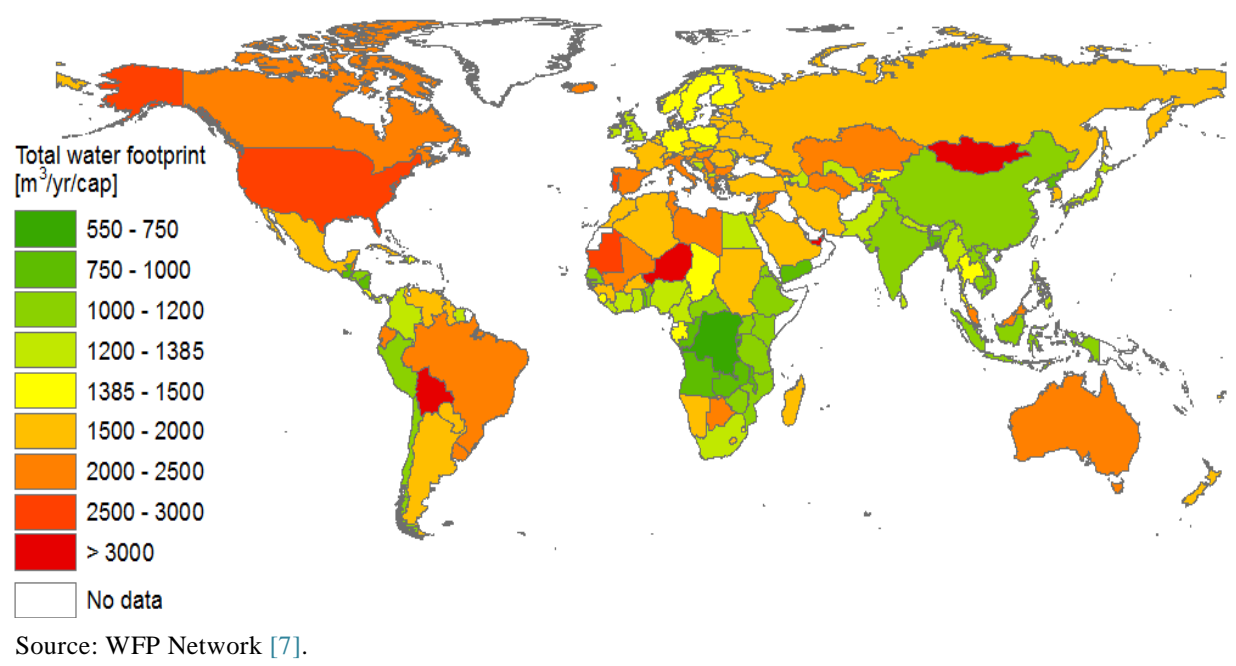

Figure 2. World-wide water foot print per capita.

population in most poor countries. Herein, Africa is naturally less endowed against India and China’s population share lowering the per capita water footprint.

However, as shown by Bhattacharya and Sinha [8], water scarcity has risen between 1990 and 2012. For a sample of 188 countries, they categorically show that disparity per capita water availability disparities has increased at within-group as well as between group levels.

Water is often misunderstood in binary terms as if it is available till it is there and will suddenly become unavailable. The problem with such binary approach is that policymakers often treat water as a non-economic commodity, which is given by the nature and would remain present in abundant supply. Therefore, the present day impact of shortage of water is often ignored or underplayed. However, Hanemann [9] presents a very convincing argument about why water should be considered an economic commodity. Going a step further, Sullivan [10] and Lawrence, Meigh and Sullivan [11] calculate a water poverty index for the world. The measure provides an understanding of the impact of water deprivation on increase in poverty.

In the present study, an attempt has been made to compute inequality in access to improved water source among 188 countries spanning over six groups by means of Theil's second measure [12], as this index permits inequalities to be categorized within and between groups. Traditionally, this index is used to calculate inequalities in several contexts [8] [13]-[19], and as it is comparable in nature, it has a vivid acceptance among the scholars. While analyzing relative inequality, this index allows cross-time evaluation within individual groups, and across the groups as well. In course of the analysis carried out in the present study, it has been tried to present both of the said facets of proportional analysis, which have mostly been ignored in the literature, considering the analysis of inequality in access to improved water source. Using Theil's second measure, this analysis is targeted towards addressing the research gap identified in the literature.

\section{Methodology}

Following the information entropy measure given by Shannon [20], the generalized outline of entropy in the form of Theil index is given by the following:

$$
E=-k \sum_{1}^{N}\left(p_{i} \log p_{i}\right)
$$

where, $p_{i}$ is the probability of access to improved water source $y_{i}$ of a person among the population of $N$, and the total access to improved water source of the population can be given by $N \hat{y}, \hat{y}$ being the average water availability of the population. Therefore, the observed entropy represented by Theil index is given by:

$$
E=\sum_{1}^{N}\left(\frac{y_{i}}{N \hat{y}} \log \frac{N \hat{y}}{y_{i}}\right)
$$

Assuming the uniformity among the population, it can be said that $p_{i}=1 / N$. In that case, Equation (2) takes 
the following form:

$$
E=\frac{1}{N} \sum_{1}^{N}\left(\log \frac{N \hat{y}}{y_{i}}\right)
$$

It is the boundary condition of Theil's basic measure, where the scalar multiplier value is approximated to zero [21], as per the following:

$$
E=\lim _{c \rightarrow 0}\left[\frac{1}{N} \frac{1}{c(c-1)} \sum_{1}^{N}\left\{\left(\frac{y_{i}}{N \hat{y}}\right)^{c}-1\right\}\right]=\frac{1}{N} \sum_{1}^{N} \log \left(\frac{N \hat{y}}{y_{i}}\right)
$$

This is the form of Atkinson's index [22] along the lines of a utilitarian social welfare function with utility of improved water availability presented in a logarithmic form. This form is commonly known as Theil's second measure.

The Theil's second measure can be split into two fundamental and analogous elements, namely a withingroup inequality element, calculated as the weighted average of the intra-group inequality indices; and a between-group inequality element, denoting the inequalities that can emerge, if only deviations exist among averages of the individual groups [12]. The index can be defined in the following manner:

$$
T_{i}=\sum_{i=1}^{n} p_{i} \log \left(\frac{\bar{W}}{W_{i}}\right)
$$

where, $p_{i}$ stands for population percentage of country $i, w_{i}$ stands for per capita access to improved water source in country $i$, and $\hat{w}$ stands for average per capita access to improved water source. In keeping with the standard mean logarithmic deviation and the approximations mentioned by Theil [12], range of Theil's second measure can be defined as $(0,1)$, where values close to zero can be taken as near to perfect equality condition, and values near to one as close to perfect inequality condition. The disintegration of $T_{i}$ can be shown in the following manner:

$$
T_{i}=T_{w g}+T_{b g}=\sum_{i=1}^{g} p_{g} \log \left(\frac{\bar{W}}{W_{i}}\right)
$$

where, $T_{w g}$ stands for the absolute within-group inequality element, $T_{b g}$ stands for the absolute between-group inequality element, and $p_{g}$ stands for population percentage of group $g$.

Annual data for access to improved water source and population have been collected from World Bank indicators (http://data.worldbank.org/indicator). There are two major variables considered in this study. First one is per capita access to improved water source, and the second one is population. Data for these two variables are collected individually for 188 countries, and the discussed Theil index has been measured based on these two variables. Duration of the study is 1990-2012, and our sample includes African countries (52), Asian and Oceanian countries (40), Central and South American countries (36), European countries (43), Middle East countries (13), and North American countries (4).

\section{Results and Analysis}

The results are shown in Table 2 and Table 3. The results recorded in Table 2 reveal the disintegration of Theil index into within-group and between-group components, and the results recorded in Table 3 divulge the contribution of all of the six groups to within-group inequality component. Figure 3 is the graphical demonstration of the Theil indices recorded in Table 2, and Figure 4 demonstrates the movement of between-group inequality components recorded in Table 3. Now, we will explore these figures, so that some significant insights about the inequality in access to improved water source can come out.

In view of the obtained results, following observations have emerged:

First, the inequalities in access to improved water source across the groups are showing a descending movement all through the study period, and the Theil index has declined by nearly 63.44 per cent.

Second, the disintegration of Theil index into within-group and between-group components can divulge the rationale behind this decline, which has hardly been looked into the literature. While reviewing this result, it should be kept in mind that the movement of Theil index towards equality has taken place in the context of 
Table 2. Theil index for all the countries (including within-group and between-group inequality components).

\begin{tabular}{|c|c|c|c|c|c|}
\hline \multirow{2}{*}{ Year } & \multicolumn{5}{|c|}{ Theil indices $^{\mathrm{a}}$} \\
\hline & $T_{w g}$ & $T_{b g}$ & $T_{i}$ & $T_{w g}(\%)$ & $T_{b g}(\%)$ \\
\hline 1990 & 0.05162 & 0.06897 & 0.12059 & 42.80 & 57.20 \\
\hline 1991 & 0.05031 & 0.06654 & 0.11685 & 43.05 & 56.95 \\
\hline 1992 & 0.04929 & 0.06454 & 0.11384 & 43.30 & 56.70 \\
\hline 1993 & 0.04780 & 0.06154 & 0.10934 & 43.72 & 56.28 \\
\hline 1994 & 0.04775 & 0.05932 & 0.10706 & 44.60 & 55.40 \\
\hline 1995 & 0.04616 & 0.05667 & 0.10283 & 44.89 & 55.11 \\
\hline 1996 & 0.04301 & 0.05283 & 0.09584 & 44.87 & 55.13 \\
\hline 1997 & 0.04003 & 0.04979 & 0.08982 & 44.57 & 55.43 \\
\hline 1998 & 0.03743 & 0.04682 & 0.08426 & 44.43 & 55.57 \\
\hline 1999 & 0.03509 & 0.04433 & 0.07942 & 44.19 & 55.81 \\
\hline 2000 & 0.03292 & 0.04210 & 0.07502 & 43.88 & 56.12 \\
\hline 2001 & 0.03102 & 0.03983 & 0.07084 & 43.78 & 56.22 \\
\hline 2002 & 0.02952 & 0.03805 & 0.06757 & 43.68 & 56.32 \\
\hline 2003 & 0.02780 & 0.03639 & 0.06419 & 43.31 & 56.69 \\
\hline 2004 & 0.02594 & 0.03484 & 0.06078 & 42.68 & 57.32 \\
\hline 2005 & 0.02463 & 0.03330 & 0.05792 & 42.51 & 57.49 \\
\hline 2006 & 0.02305 & 0.03207 & 0.05512 & 41.82 & 58.18 \\
\hline 2007 & 0.02170 & 0.03088 & 0.05258 & 41.27 & 58.73 \\
\hline 2008 & 0.02005 & 0.03005 & 0.05010 & 40.02 & 59.98 \\
\hline 2009 & 0.01872 & 0.02913 & 0.04784 & 39.12 & 60.88 \\
\hline 2010 & 0.01769 & 0.02829 & 0.04598 & 38.48 & 61.52 \\
\hline 2011 & 0.01513 & 0.02889 & 0.04402 & 34.38 & 65.62 \\
\hline 2012 & 0.01445 & 0.02964 & 0.04409 & 32.77 & 67.23 \\
\hline
\end{tabular}

${ }^{\mathrm{a} S}$ Source: authors' own calculations.

Table 3. Breakup of the between-group inequality component.

\begin{tabular}{ccccccc}
\hline \multirow{2}{*}{ Year } & \multicolumn{5}{c}{ Group-wise between-group inequality components ${ }^{\mathrm{a}}$} \\
\cline { 2 - 7 } & Africa & Asia \& Oceania & Central \& South America & Europe & Middle East & North America \\
\hline 1990 & 0.16613 & 0.07767 & 0.00684 & 0.00861 & 0.04926 & 0.05386 \\
1991 & 0.16431 & 0.07353 & 0.00757 & 0.00838 & 0.05006 & 0.05132 \\
1992 & 0.16263 & 0.07000 & 0.00860 & 0.00812 & 0.05148 & 0.04939 \\
1993 & 0.15195 & 0.06664 & 0.00915 & 0.00786 & 0.05361 & 0.04726 \\
1994 & 0.14390 & 0.06410 & 0.00978 & 0.00761 & 0.05581 & 0.04536 \\
1995 & 0.13637 & 0.06079 & 0.01039 & 0.00735 & 0.05834 & 0.04324 \\
1996 & 0.13003 & 0.05508 & 0.01103 & 0.00699 & 0.06027 & 0.04170 \\
1997 & 0.12427 & 0.05072 & 0.01172 & 0.00677 & 0.06229 & 0.03954 \\
1998 & 0.11921 & 0.04643 & 0.01203 & 0.00652 & 0.06405 & 0.03738 \\
1999 & 0.11556 & 0.04254 & 0.01288 & 0.00621 & 0.06597 & 0.03581 \\
2000 & 0.11262 & 0.03906 & 0.01379 & 0.00587 & 0.06785 & 0.03364 \\
2001 & 0.10999 & 0.03543 & 0.01364 & 0.00557 & 0.06971 & 0.03243 \\
2002 & 0.10828 & 0.03251 & 0.01416 & 0.00527 & 0.07181 & 0.03025 \\
2003 & 0.10660 & 0.02986 & 0.01462 & 0.00481 & 0.07320 & 0.02808 \\
\hline
\end{tabular}




\begin{tabular}{ccccccc}
\multicolumn{2}{l}{ Continued } & \multicolumn{7}{l}{} \\
\hline 2004 & 0.10515 & 0.02724 & 0.01449 & 0.00455 & 0.07471 & 0.02686 \\
2005 & 0.10345 & 0.02470 & 0.01492 & 0.00439 & 0.07609 & 0.02506 \\
2006 & 0.10182 & 0.02277 & 0.01486 & 0.00426 & 0.07771 & 0.02291 \\
2007 & 0.10030 & 0.02085 & 0.01482 & 0.00409 & 0.07916 & 0.02112 \\
2008 & 0.09891 & 0.01939 & 0.01528 & 0.00394 & 0.08077 & 0.01992 \\
2009 & 0.09756 & 0.01794 & 0.01530 & 0.00367 & 0.08151 & 0.01814 \\
2010 & 0.09605 & 0.01661 & 0.01535 & 0.00367 & 0.08257 & 0.01637 \\
2011 & 0.09451 & 0.01800 & 0.01560 & 0.00367 & 0.08171 & 0.01461 \\
2012 & 0.09261 & 0.01961 & 0.01619 & 0.00365 & 0.08159 & 0.01343 \\
\hline
\end{tabular}

a Source: Authors' own calculations.

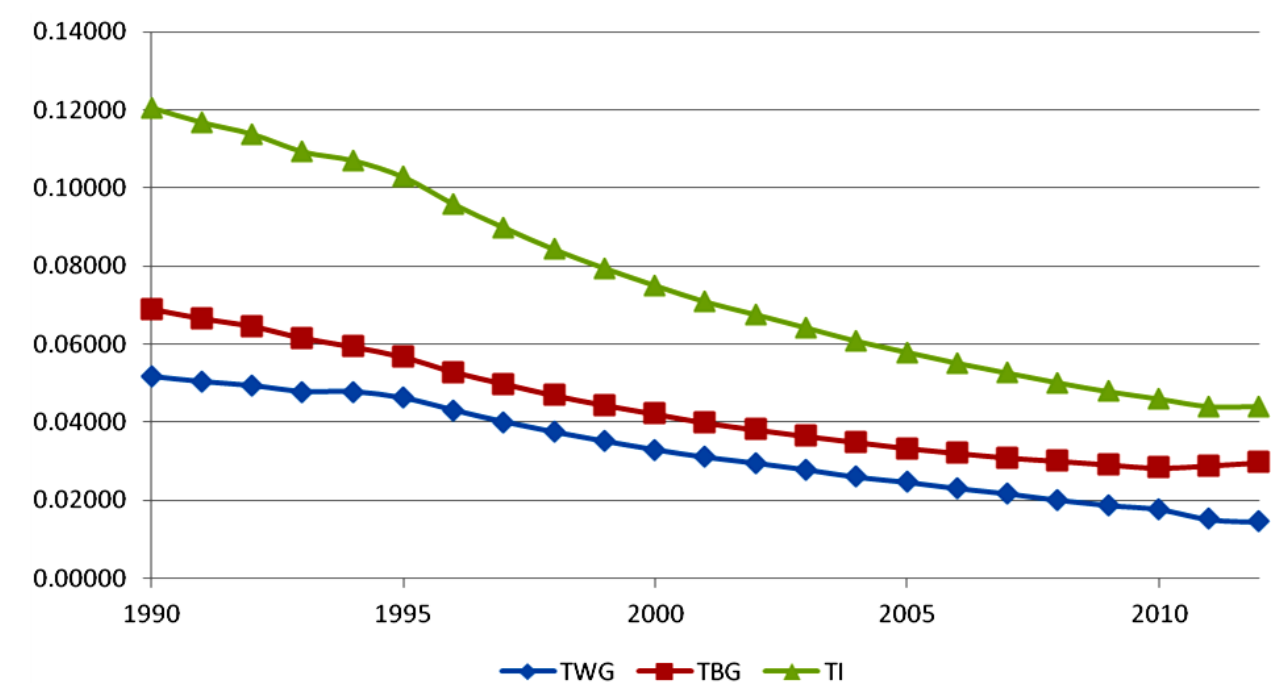

Figure 3. Movement of Theil indices (within-group, between-group, and composite).

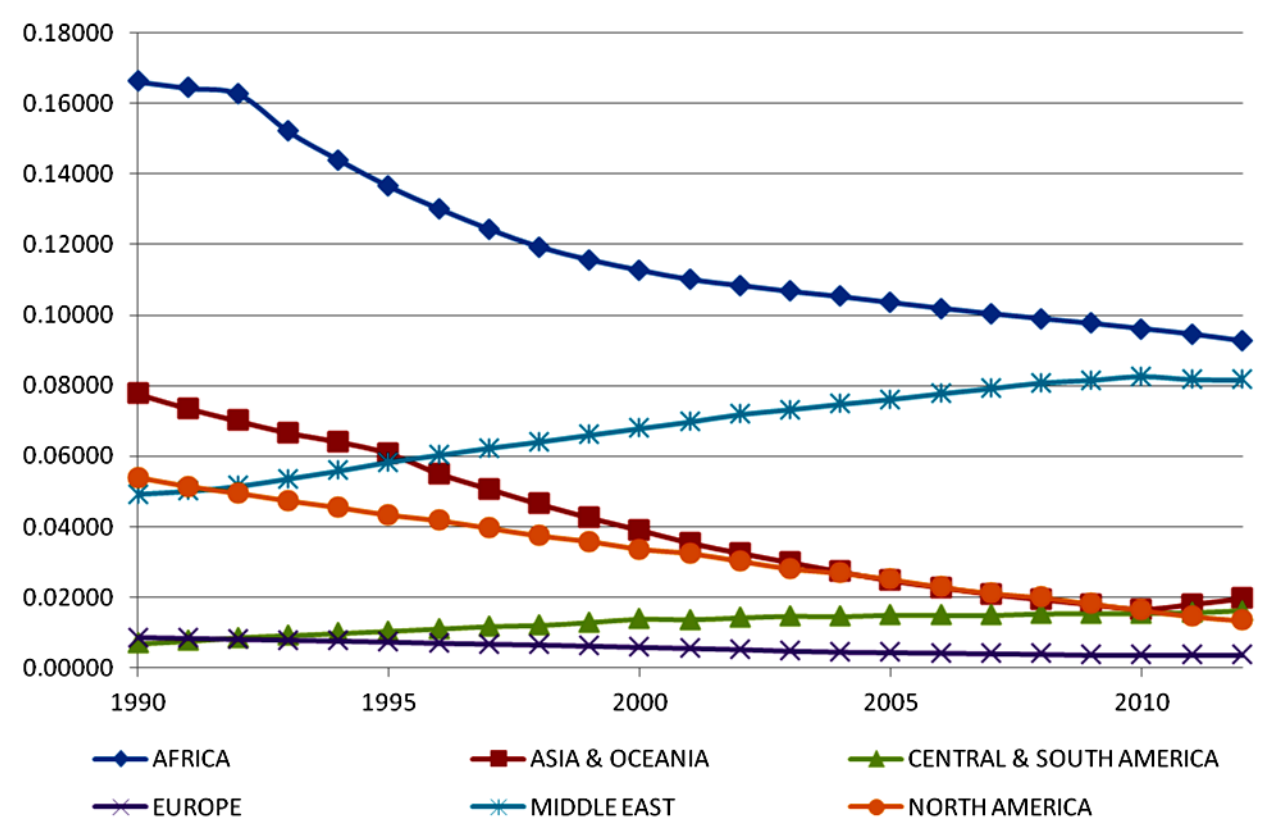

Figure 4. Movement of betweeen group inequality component for all the six groups of countries. 
rising access to improved water source. Therefore, keeping Middle East countries and Central \& South American apart, rest four of the groups have shown the descending trend all through the study period. This incident can be attributed to the countries, like Sudan, Yemen, Brazil, and Dominican Republic, where the per capita access to improved water source is comparatively poor, with populations more than the group average, thereby, adding to the between-group inequality component.

Third, by observing the results, it can be witnessed that out of the two basic elements of the Theil index, the between-group component $\left(T_{b g}\right)$ contributes more towards the inequality scenario, as it accounts for almost 57.91 percent of the aggregate inequality. This component can prove to be noteworthy in view of divergent rate of growth achieved by these nations, the distribution of population, socio-economic constitution of these nations, the technological expansion and environmental concerns, and lastly, disparity in geological and climatic conditions. Conceivably that is the reason behind the exhibition of low Theil index for European, North American, and Asian and Oceanian countries, and comparatively higher Theil index for African, Middle East, and Central and South American countries. The inequality scenario for countries pertaining to Asia and Oceania has been improving radically over the years, whereas, for the African countries, even after the decline in Theil index, the inequality is quite higher compared to the other groups. Among all of the six groups, North American countries have shown a decline of 75.06 percent in inequality, whereas Asian and Oceanian countries have shown the same by 74.75 percent, followed by 57.61 percent for European countries, and 44.25 per cent for African countries. Middle East countries and Central and South American countries have shown a rise of 65.62 percent and 136.68, respectively, in the inequality.

\section{Conclusions}

By means of the Theil index, we have learned that during 1990-2012, several countries across the world lowered the disparities in access to improved water source within the context of a general improvement in access levels, with the exception of the Central and South American countries and Middle East countries. This index has furthermore allowed us to demonstrate two key observations: first, the decrease in inequality in access to improved water source can be elucidated by within-group and between-group inequality components; second, betweengroup inequality component is the key contributor to the inequality estimation.

In a few words, these results can elicit two corresponding themes of research concerning water preservation strategies: first, the practices, through which a convergence towards per capita availability of water can be achieved in the context of increasing accessibility of water from healthier sources, can be scrutinized; and second, explaining the ways, which catalyze the intercontinental diffusion of technologies, international affairs, ecological concerns, and consumption pattern. These are the four factors, which can bring forth disparities in the per capita access to improved water source among the nations, and thereby, can define the rise in between-group inequality component.

\section{References}

[1] Bajaj, V. (2012) Crops in India Wilt in a Weak Monsoon Season. http://www.nytimes.com/2012/09/04/business/global/drought-in-india-devastates-crops-and-farmers.html

[2] GoI (2015) https://data.gov.in/

[3] PIB (2012) Per Capita Water Availability. http://pib.nic.in/newsite/erelease.aspx?relid=82676

[4] Google Public Data (2015) Annual Freshwater Withdrawals, Total (\% of Internal Resources). http://www.google.com/publicdata/explore?ds=d5bncppjof8f9_\&ctype=l\&met_y=er_h2o_fwtl_zs\#!ctype=l\&strail=fal se\&bcs=d\&nselm=h\&met_y=er_h2o_fwtl_zs\&scale_y=lin\&ind_y=false\&rdim=region\&idim=country:IND:USA:AUS :CHN:ARG:ZAF\&ifdim=region\&hl=en_US\&dl=en_US\&ind=false

[5] WSJ (2015) China’s Water Problems Are Even Worse than You Think: Report. http://blogs.wsj.com/chinarealtime/2015/01/13/chinas-water-problems-are-even-worse-than-you-think-report/

[6] Global Change (2000) Human Appropriation of the World's Fresh Water Supply. http://www.globalchange.umich.edu/globalchange2/current/lectures/freshwater_supply/freshwater.html

[7] WFP Network (2015) Water Footprint Statistics (WaterStat). http://waterfootprint.org/en/resources/water-footprint-statistics/

[8] Bhattacharya, J. and Sinha, A. (2015) Inequality in per Capita Water Availability: A Theil’s Second Measure Approach. Desalination and Water Treatment, 1-9. http://dx.doi.org/10.1080/19443994.2015.1006818 
[9] Hanemann, W.M. (2006) The Economic Conception of Water. In: Rogers, P.P., Llamas, M.R. and Martinez-Cortina, L., Eds., Water Crisis: Myth or Reality? Taylor \& Francis, New York, 61-91. http://dx.doi.org/10.1201/9781439834275.pt2a

[10] Sullivan, C. (2002) Calculating a Water Poverty Index. World Development, 30, 1195-1210. http://dx.doi.org/10.1016/S0305-750X(02)00035-9

[11] Lawrence, P., Meigh, J. and Sullivan, C. (2002) The Water Poverty Index: An International Comparison. Keele Economics Research Papers, Kerp 2002/19. www.keele.ac.uk/depts/ec/web/wpapers/kerp0219.pdf

[12] Theil, H. (1967) Economics and Information Theory. North-Holland Publishing Company, Amsterdam.

[13] Conceição, P., Galbraith, J.K. and Bradford, P. (2001) The Theil Index in Sequences of Nested and Hierarchic Grouping Structures: Implications for the Measurement of Inequality through Time, with Data Aggregated at Different Levels of Industrial Classification. Eastern Economic Journal, 27, 491-514.

[14] Alcantara, V. and Duro, J.A. (2004) Inequality of Energy Intensities across OECD Countries: A Note. Energy Policy, 32, 1257-1260. http://dx.doi.org/10.1016/S0301-4215(03)00095-8

[15] Akita, T. (2003) Decomposing Regional Income Inequality in China and Indonesia Using Two-Stage Nested Theil Decomposition Method. The Annals of Regional Science, 37, 55-77. http://dx.doi.org/10.1007/s001680200107

[16] Murray, S.E., Evans, W.N. and Schwab, R.M. (1998) Education-Finance Reform and the Distribution of Education Resources. American Economic Review, 88, 789-812.

[17] Cowell, F.A. (1985) Multilevel Decomposition of Theil’s Index of Inequality. Review of Income and Wealth, 31, 201205. http://dx.doi.org/10.1111/j.1475-4991.1985.tb00508.X

[18] Akita, T., Lukman, R.A. and Yamada, Y. (1999) Inequality in the Distribution of Household Expenditures in Indonesia: A Theil Decomposition Analysis. The Developing Economies, 37, 197-221. http://dx.doi.org/10.1111/j.1746-1049.1999.tb00231.x

[19] Duro, J.A. and Esteban, J. (1998) Factor Decomposition of Cross-Country Income Inequality, 1960-1990. Economics Letters, 60, 269-275. http://dx.doi.org/10.1016/S0165-1765(98)00113-X

[20] Shannon, C.E. (1951) Prediction and Entropy of Printed English. Bell System Technical Journal, 30, 50-64. http://dx.doi.org/10.1002/j.1538-7305.1951.tb01366.x

[21] Shorrocks, A. (1980) The Class of Additively Decomposable Inequality Measures. Econometrica, 48, 613-625. http://dx.doi.org/10.2307/1913126

[22] Atkinson, A.B. (1970) On the Measurement of Inequality. Journal of Economic Theory, 2, 244-263. http://dx.doi.org/10.1016/0022-0531(70)90039-6 